\title{
PROPOSAL OF CONTENT MAINTENANCE OF CNC MACHINE USING METHODS OF RELIABILITY CENTERED MAINTENANCE
}

\author{
Vladimír Stuchlý1, Roman Poprocký1, Nadežda Čuboňová1, Ivan Kuric ${ }^{1}$ \\ 1 University of Žilina, Faculty of Mechanical Engineering, Univerzitna 1, 010 26, Žilina, Slovakia \\ e-mail:vladimir.stuchly@fstroj.uniza.sk, roman.poprocky@fstroj.uniza.sk, nadezda.cubonova@fstroj.uniza.sk, \\ ivan.kuric@fstroj.uniza.sk
}

Received: 2018.05.16

Accepted: 2018.08.01

Published: 2018.09.01

\begin{abstract}
The paper presents the results of examination of the proposal content and the scope of maintenance of the machining center MCFV 1050 Basic through the RCM II - Reliability Centered Maintenance method. Based on the analysis of apriori and parametric reliability methods, it was decided to use the FMEA for analyze the causes and consequences of failure states using the software IQ-RM PRO 6. The structure, defined functions and fault functions were developed.The analyzed types of failure and types of maintenance tasks were processed in the RCM II Information and Decision Making Reports. The result is 10 proposed maintenance tasks performed in time intervals, 8 maintenance tasks performed as needed and 1 maintenance task performed after the specified performance.The end of the article discusses the suitability of the applied methods for the maintenance proposal and of the defined recommendations.
\end{abstract}

Keywords: maintenance, reliability, reliability centerd maintenance.

\section{INTRODUCTION}

In traditional maintenance approach the requirements on maintenance of each component were determined in accordance with its actual or assumed technical characteristics, without considering its failure consequences. The resulting schedules were used to all similar objects without considering different consequences coming from different operational contexts.

For utilization of reliability parameters in machines and equipment maintenance it is necessary to answer also the questions such as:

- How can the reliability parameters be found out?

- Is there a reason for their determination?

- Is there a reason to investigate components or the whole systems?

- Which reliability parameters have the main importance for maintenance? And do they have any importance?

- How, when, where and in what extent should these reliability parameters be determined?
- How can the calculation of reliability parameters help creating maintenance systems?

Reliability of already operated machines and equipment (because these are in the focus of maintenance) was built in during the design and manufacture phase. Maintenance itself can not improve the built in (inherent) reliability. Then for overall quality of machines and equipment it should be distinguished [1].

From long-term experience in engineering it is evident that the machines reliability can be improved by:

- Selection of better (but more expensive) components,

- Increase of reliability of functionally linked components,

- Reducing the number of components that are functional in series (serial systems),

- By redundancy (component or total) of less reliable components,

- Running-in, avoiding the initial failures,

- By protection against damaging effects 
(trained operators, suitable operational conditions etc.)

Reliability theory studies rules of failure in objects (in general of machines an equipment) and methods of their prediction, it searches possibilities of increasing reliability of objects in all stages of their design and utilization. It deals with quantitative reliability parameters, economic and effectiveness characteristics. Legát et. al. [14]present a method for determining the optimal interval for preventive periodical maintenance and an optimal diagnostic parameter for predictive maintenance/replacement [3, 20]. Additionally, the authors raise the question: how does preventive maintenance influence the probability of failure and the operational reliability of system elements that have undergone preventive periodical maintenance? They answer the question using analytical and simulation computing approaches. The results are in quantitative form, giving relationships between preventive maintenance intervals and reliability functions. Examples demonstrate suitability of the method for typical engineering objects using a three parameters Weibull distribution. Application of the method is of substantial benefit to both the manufacturer and the user of technical equipment.This methodology is also presented in $[2,7,12,17,21]$.

Why it is not always correct and effective use methods posterior confidence? A surprising number of people believe that effective maintenance policy can be formulated only on the basis of historical information about failure. It leads also to put great emphasis on fault patterns described for examle in literature $[4,13,16]$. In terms of maintenance failure patterns are fraught practical difficulties, riddles and contradictions. Some are recapitulated in the following points: complexity - the majority of industrial enterprises consist of hundreds, if not thousands of different objects. These are made up of dozens of different components, which between them exhibit every extreme and intermediate of reliability behavior. This combination of complexity and diversity means that is simply not possible to develop a complete description of the reliability characteristics of an entire undertaking - or even any major asset in the enterprise. Reporting failure - the problem of analyzing failure data is further complicated by differences in reporting policy from one organization to another. One area of confusion is the difference between the potential and functional failures $[5,16]$. Sample size and evolution - large industrial processes usually posses only one or two assets of any type. They also tend to be brought into operation in series rather than simultaneously. This means that sample sizes tend to be too small for statistical procedures to carry much conviction. Final opposites - output, which introduced confusion into the whole problem of technical history is the fact that if you gather information about fault, fails to be so even preventing them. The solution is to use methods apriori reliability, extended the RCM II $[9,10,15]$.

Reliability-centered maintenance (RCM) evolved in the airline industry during thr 1960s and 1970s from the original work of the methods originators - F. Stanley Nowlan and Howard F Heap [16], but also [15]. Nowlan and Heap stated that the logic of RCM is based on three questions, viz.:

1. How does a failure occur?

2. What are its consequences for safety or operability?

3. What good can preventive maintenance do? And they further emphasized that, in RCM:"The driving element in ail maintenance decisions is not the failure of a given item, but the consequence of that failure for the equipment as a whole".

\section{The RCM procedure}

Fig. 1 outlines firstly, in Steps 1-4, the basic structure of RCM analysis, viz.:

1. system definition and acquisition of operational and reliability information;

2. identification of maintenance significant items (MSIs) i.e. items whosefailure would significantly threaten safety or increase cost (because of loss of productionand/or high direct repair cost);

3. for each MSI, determination of the significant failure modes, their likely causes, and whether they can be detected (and if they can be, the ways in which this might be done);

4. for each significant failure mode, selection of the maintenance task, or tasks most appropriate for reducing its likelihood of occurrence or mitigating its consequences.

The analysis has to be followed by:

5. the formation of the task list into a workable plant-wide schedule;

6. implementation of the schedule and sustained feedback of in-service data for periodic review and update. 


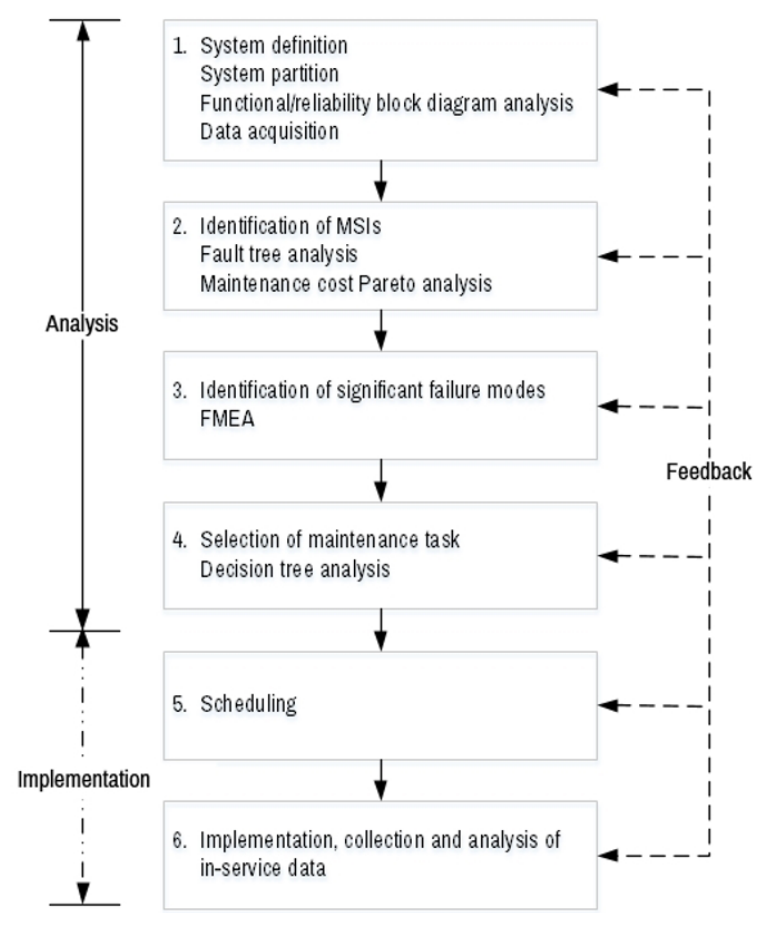

Fig. 1. Basic structure of RCM [13]

It can be seen that Steps 1-4 is a similar procedure to FMEA. The main difference is that failure modes and effects analysis (FMEA) is used in Step 3 to analyze the item into its failure modes.

Much of the analysis is a rational ordering of techniques that have long been well established and routine in reliability engineering. For example: Step 1 is basically system partitioning (separation into identifiable units) and reliability block diagram analysis.

Although Step 2, identification of the MSIs, might well beaccomplished just by reviewing history records, operator's logs and cost data to pick out the unreliable or maintenance-costly items (an activity facilitated by Pareto analysis', which is little more than sorting out the worst performers into a ranked list. e.g. of the "top ten"). Fault tree analysis might be needed, if the plant is a complex one.

It is important that any RCM procedure used should clearly define MSIs in terms of their size and complexity. If the MSIs are too large, the myriad of failure modes become unmanageable.

Step 3 is nothing more than a failure mode, effect and criticality analysis (FMECA), a stepby-step procedure for the systematic evaluation of the failure effects and the criticality of potential failure modes in equipment and plant.

In Step 4 the logical task-selection decision tree is added. It has been specially developed for
RCM and is regarded by some as the kernel of the whole approach. In this, the question repeatedly posed, in order to filter out various maintenance options, is as follows:

Is the task under consideration both applicable (Could it be done? Would it work?) and worthwhile (Would its cost, direct and indirect, be lowerthan that of just allowing the failure to occur?)?

The decision tree begins, however, with a consequence analysis, which is based on the particular form recommended by Nowlan and Heap. By its means, significant failure modes are categorized according to their consequences, which, as regards their processing in the subsequent task analysis part of the tree are prioritized, as below:

1. Hidden (or unrepealed). Increase risk from other failures (applies mostly to non-fail-safe protective equipment).

2. Safety-related or environmental. Threaten life, health or environment.

3. Operational: Threaten output, or quality of service.

4. Non-operational: Incur only direct cost of repair. Having been categorized by consequence in the upper pan of the task selection tree, each failure mode is then subject, in the lower pan, to a decision logic $[11,14]$. This leads to identification of an appropriate maintenance task or, if none can be found, to the suggestion that redesign be considered.

Note that the effect of the decision tree is to rank the task options in a definite order of preference. The analyst is directed to look firstly for a condition-based task, only secondly for a restoration (repair) task, and so forth. Implicit in the method is therefore the assumption that, where both options are viable, the condition-based one will be the more appropriate (and likewise the repair option as compared with replacement,etc.). Now, while this may well be true in most practical cases it is by no means obvious that it will be one of them. In some forms of the decision tree that have been developed the analyst (before making his final selection) is, in fact, directed to finish with a comparison of all the types of task that have been identified as viable.

\section{RELIABILITY CENTERED MAINTENANCE}

Vertical machining center MCFV 1050 Basic (Fig. 2) is a highly productive machine for complex machining of molds, dies and components of flat-shaped or box-shaped of steel, cast 


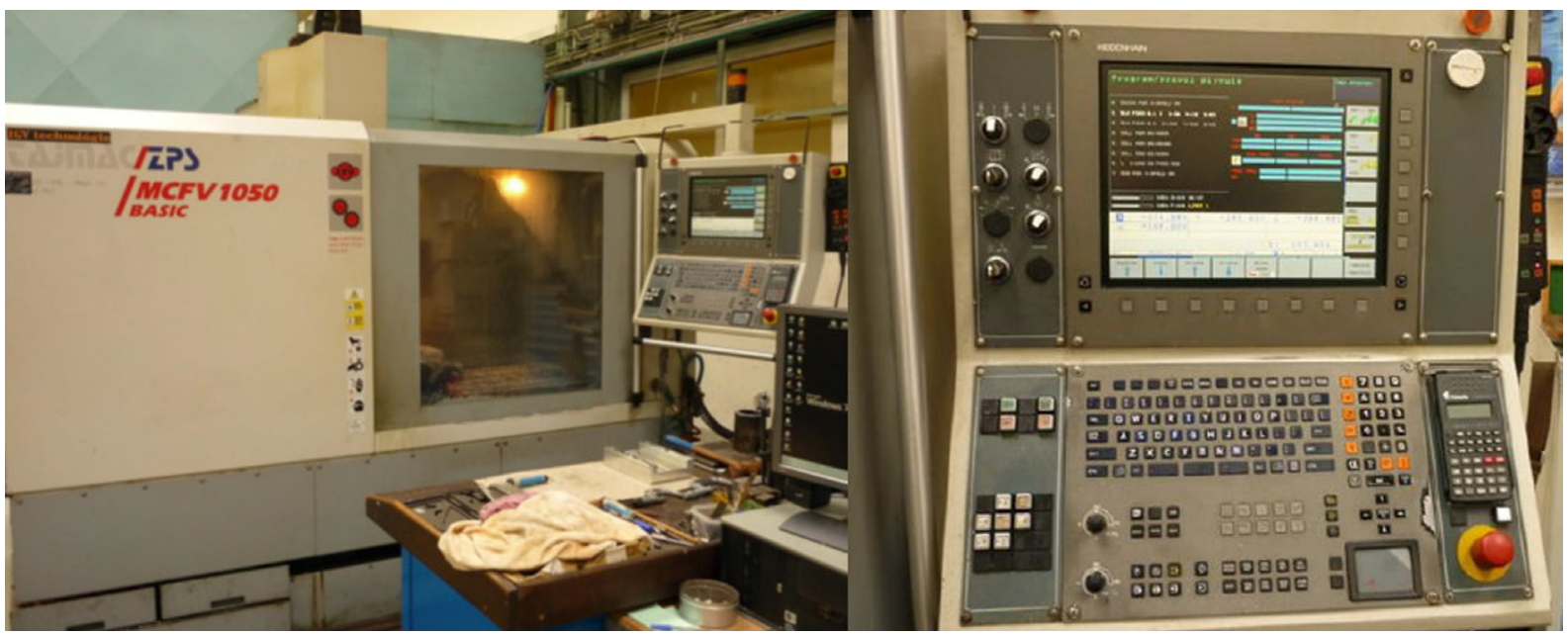

Fig. 2.Vertical machining center MCFV 1050 Basic and Control system HEIDENHAIN [6]

iron and light metal alloys clamped on the work table machine $[5,8]$.

It allows to carry out milling operations on three orthogonal coordinate axes $\mathrm{X}, \mathrm{Y}, \mathrm{Z}$ and the drilling, reaming and threading operations.

In case of $\mathrm{CNC}$ machine tool, the maintenance is focused on building components and modules of the machine tool (construction, actuators, machine control and sensors) for which required emergency of the maintained machine can be ensuredby the following steps and methods, by preventive inspections. These inspections are aimed at atcheckingof individual functional knots of the machine, such as guidance and linear axes of motion, of hydraulic system, of lubrication system and the like [18].

\section{Practical example}

Because of inaccessibility of the data from operation $\mathrm{CNC}$ machine (but in general all machines) it is not possible to use fully the methods of a posteriori reliability for creation of content and extent of maintenance [6]. So for the determination of

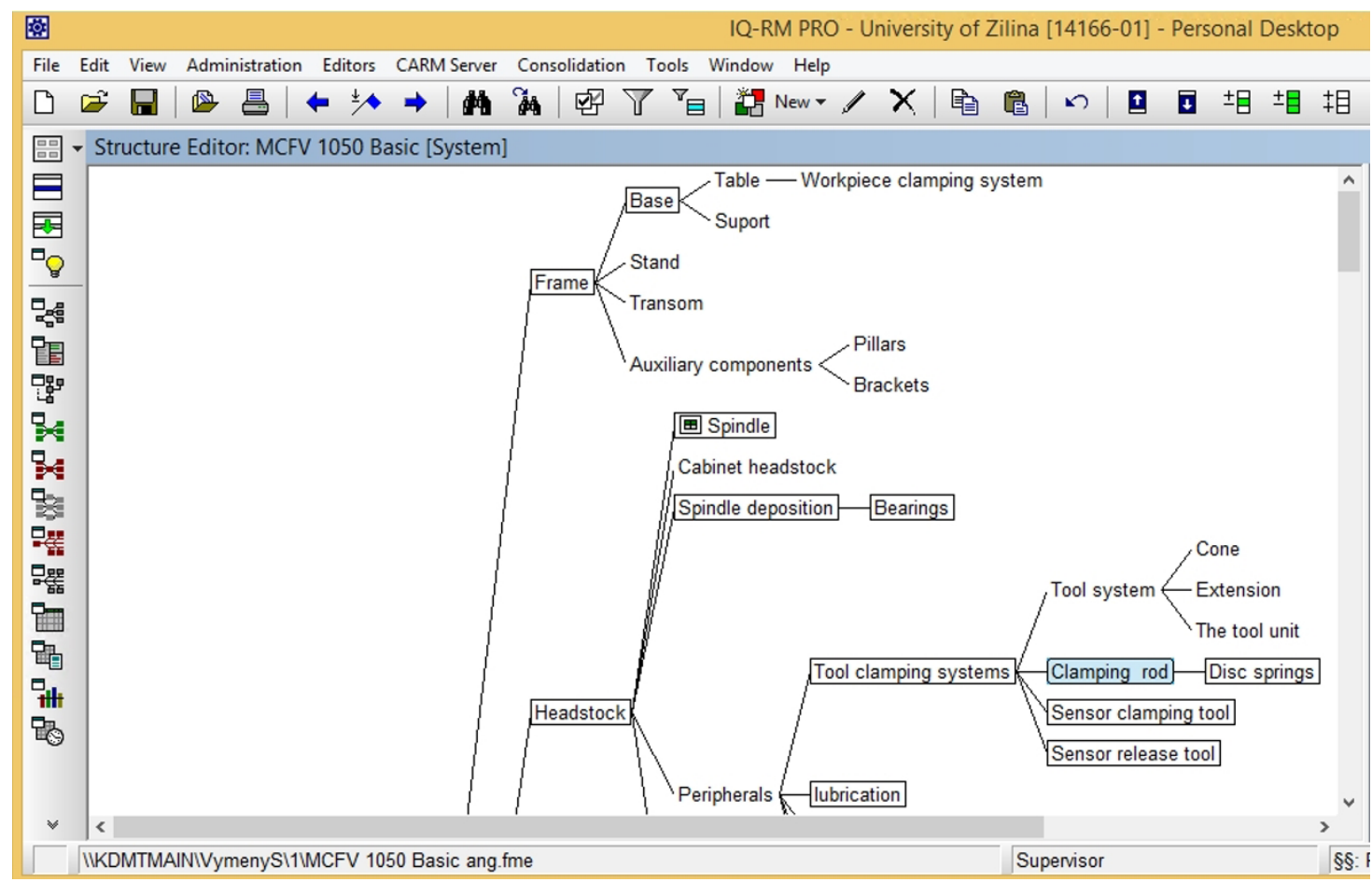

Fig. 3. Examle of structure of CNCmachine MCFV 1050 Basic 


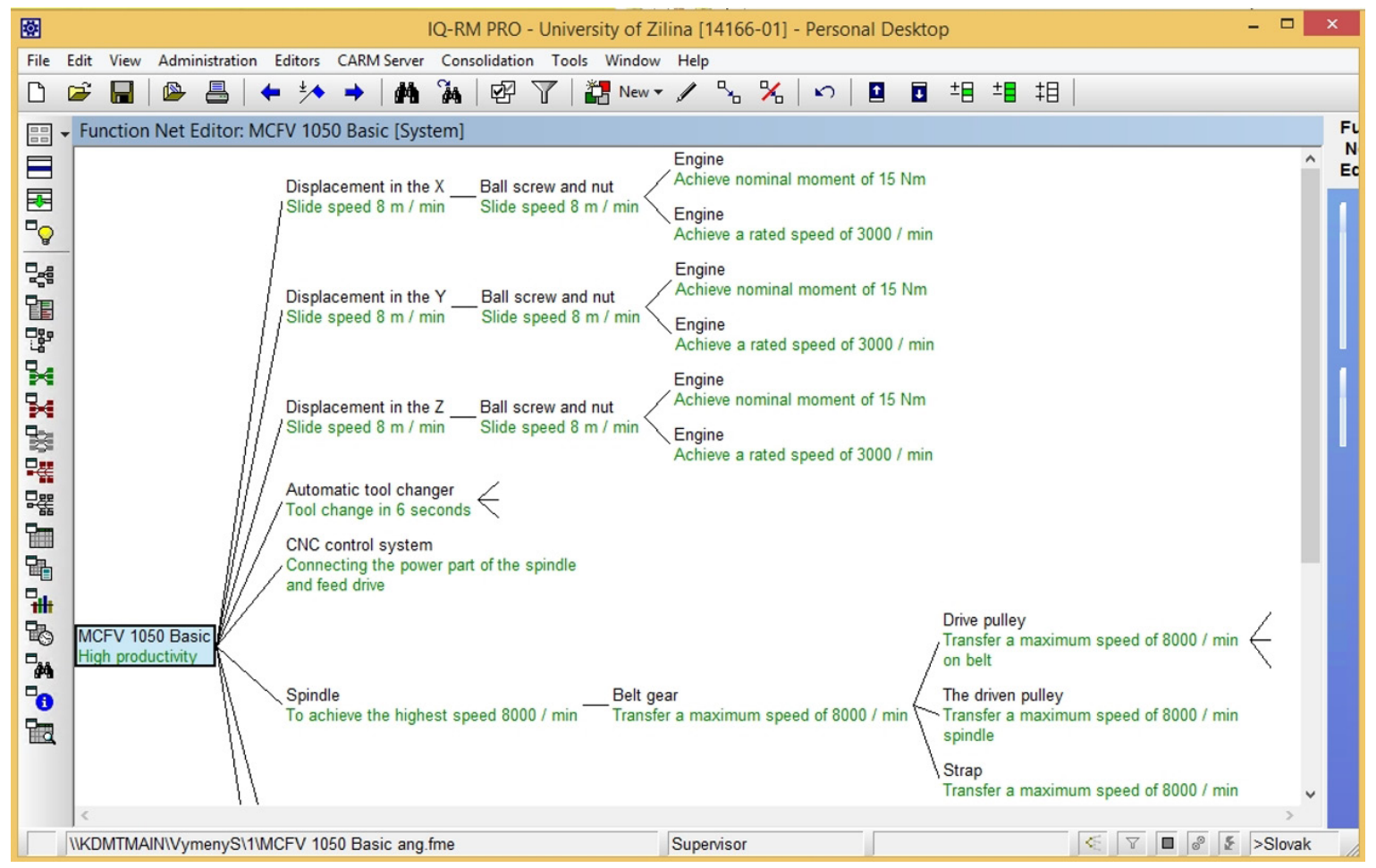

Fig. 4. Functional network for assessing the productivity of the machine

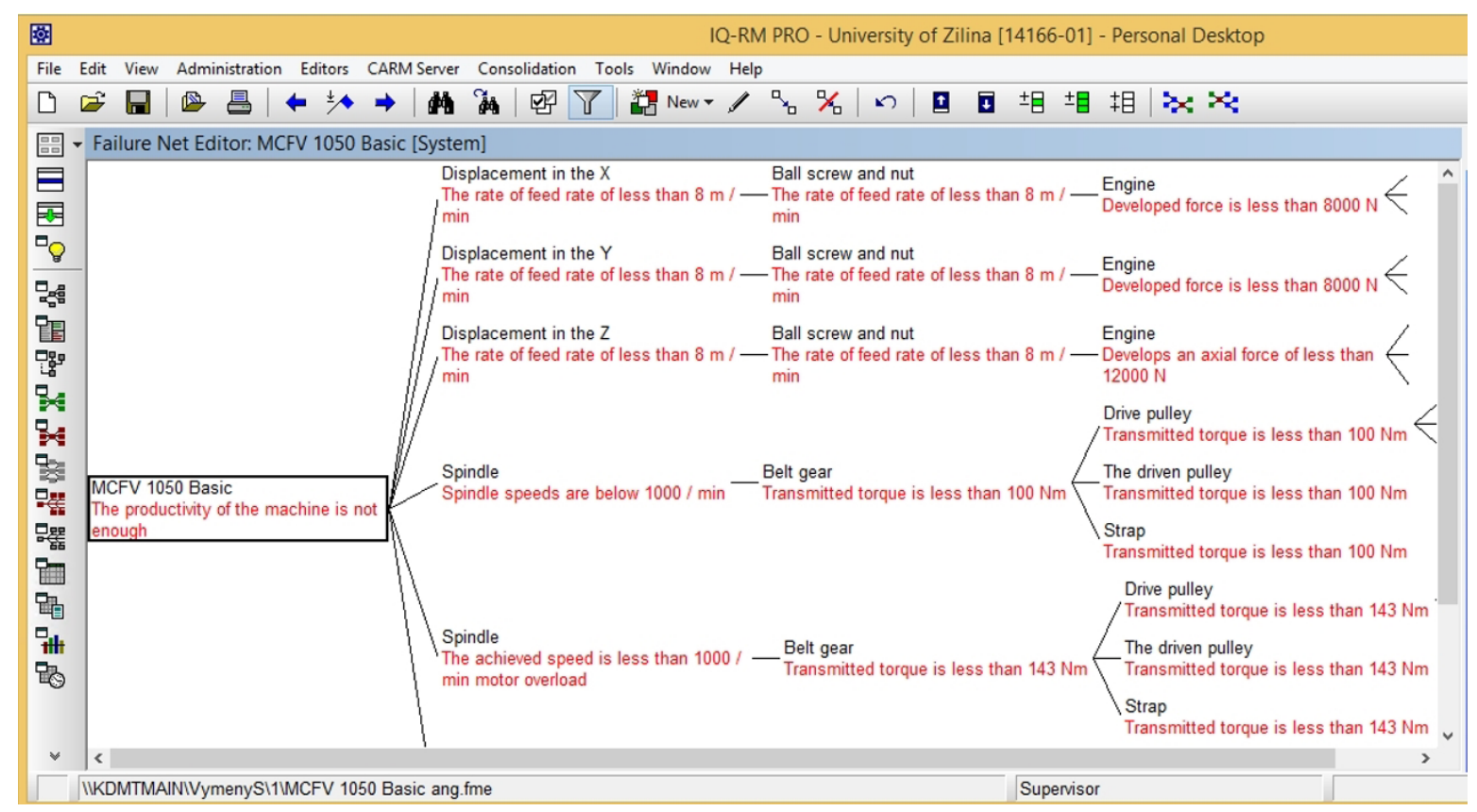

Fig. 5. The relationship between the reduced productivity of the machine and possible causes

content and extent of CNC MCFV 1050 Basic we used the method RCM II [7, 8, 13, 15, 19].

We have worked-out FMEA of CNC MCFV 1050 Basic in the software APIS PRO 6.0 with the criticality analysis, including functional and failure nets. (The software is being used at the Department of transport and handling machines), in five steps: create system elements, system struc- ture (Fig. 3), functions and function structures (Fig. 4), failure analysis (Fig. 5), risk evaluation.

The RCM were created information sheets RCM II for belt driven transmission, auto-matic tray tools, pneumatic motor tool magazine CNC control system. Reports ob-exceed functions, functional failures, fault causes and consequences of failure. 


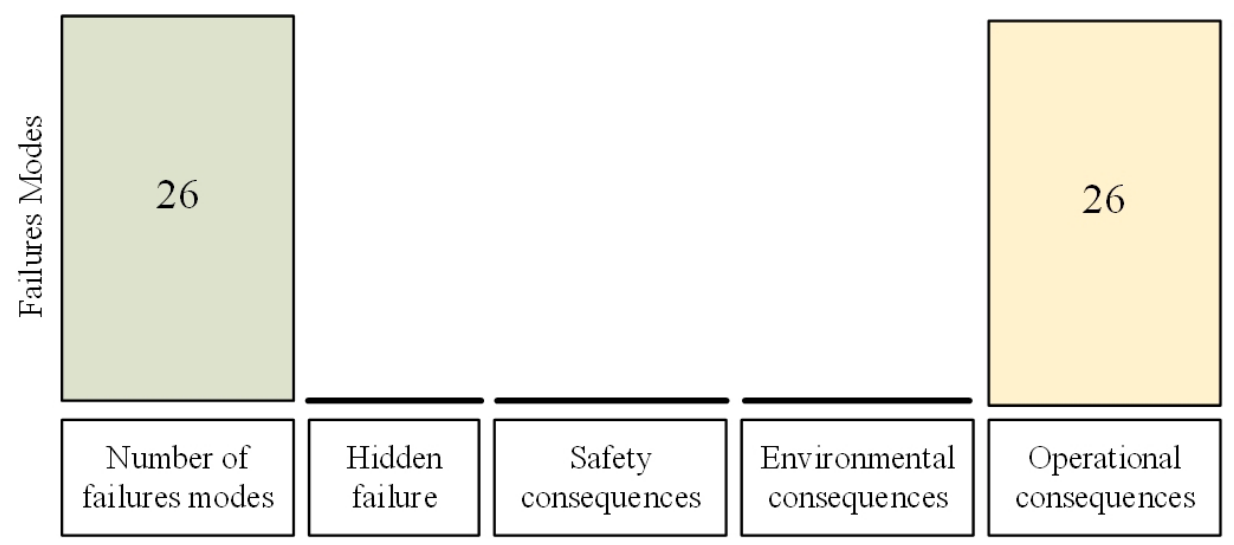

Fig. 6. Distribution of failure modes of CNC machine tool MCFV 1050

In total 26 failure modes of CNC MCFV 1050 Basicwere analysed (faults - formally failure causes and consequences) using the RCM II decision sheets. From the analyses it is concluded that during the functional loss caused by failure under operational conditions have operational consequences(evaluation in column Fig. 6). All faults are evident.

Further on, within the RCM decision sheets the preventive tasks were analysed in column H1/S1/01/N1 used for an analysis whether appropriate task for technical condition identification can be used, which enables early prediction of failure occurrence and by that avoiding its consequences. We found 17 tasks technically feasible (suitable) for prediction $(65,4 \%)$ and 9 which are not technically feasible $(34,6 \%)$ out of 142 failures considered in this analysis.

Preventive tasks in column H2/S2/02/N2 is technically feasible (suitable) for 1 task, and preventive tasks in column $\mathrm{H} 3 / \mathrm{S} 3 / 03 / \mathrm{N} 3$, is not technically feasible. In complementary questions in column H4 in RCM II decision sheet, is technically feasible task that is reasonable to carry it out in 9 task (Fig. 7).

Based on FMEA analysis of MCFV $1050 \mathrm{Ba}-$ sic and evaluation of RCM sheets for individual components of the MCFV 1050 Basic, the technical evaluation points in some case at insubstantiality of maintenance tasks during predetermined maintenance carried out according to current regulations given by the výrobca stroja MCFV 1050 Basic. According to the FMEA and RCM II evaluation, safe operation ofMCFV $1050 \mathrm{Ba}-$ sic provides space for extending the time between executions or maintenance tasks. This fact may significantly enable better utilisation of components of MCFV 1050 Basic to their limit values and from the economic point of view can reduce costs for maintenance CNC machine.

The result is thefolowing proposal: 6 maintenance tasks are performed daily, 2 maintenance tasks are performed weekly, 2 maintenance tasks are carried out at intervals of six months and 8 maintenance tasks are performed as required.The exchange of spindle bearing is estimated after performance from 8,000 to 12,000 operating hours.

Reliability, in the general concept is seen as stability of performance over a specified time and under given conditions of use. Dependability in the narrower concept (Fig.8) is an emergency as determined by three factors: reliability, maintainability and maintenance support. With

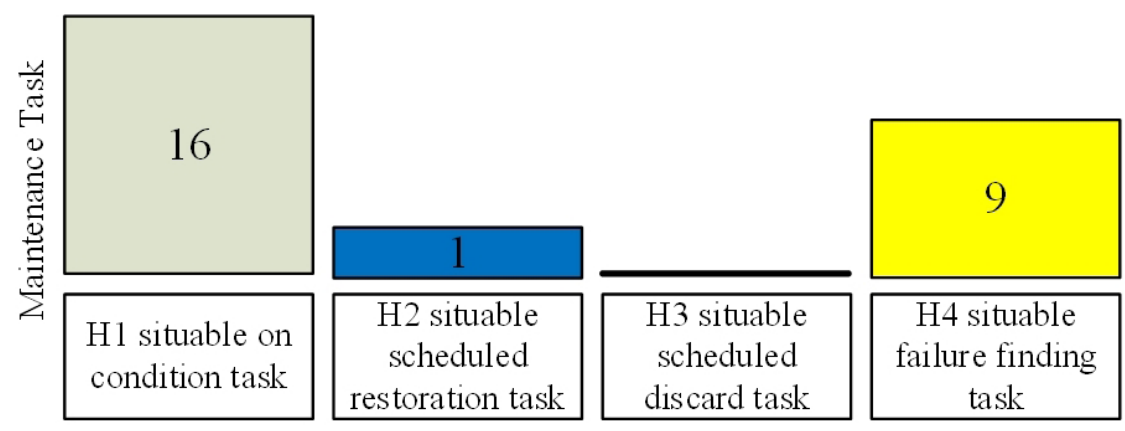

Fig. 7. Distribution of maintenance tasks for $\mathrm{CNC}$ 


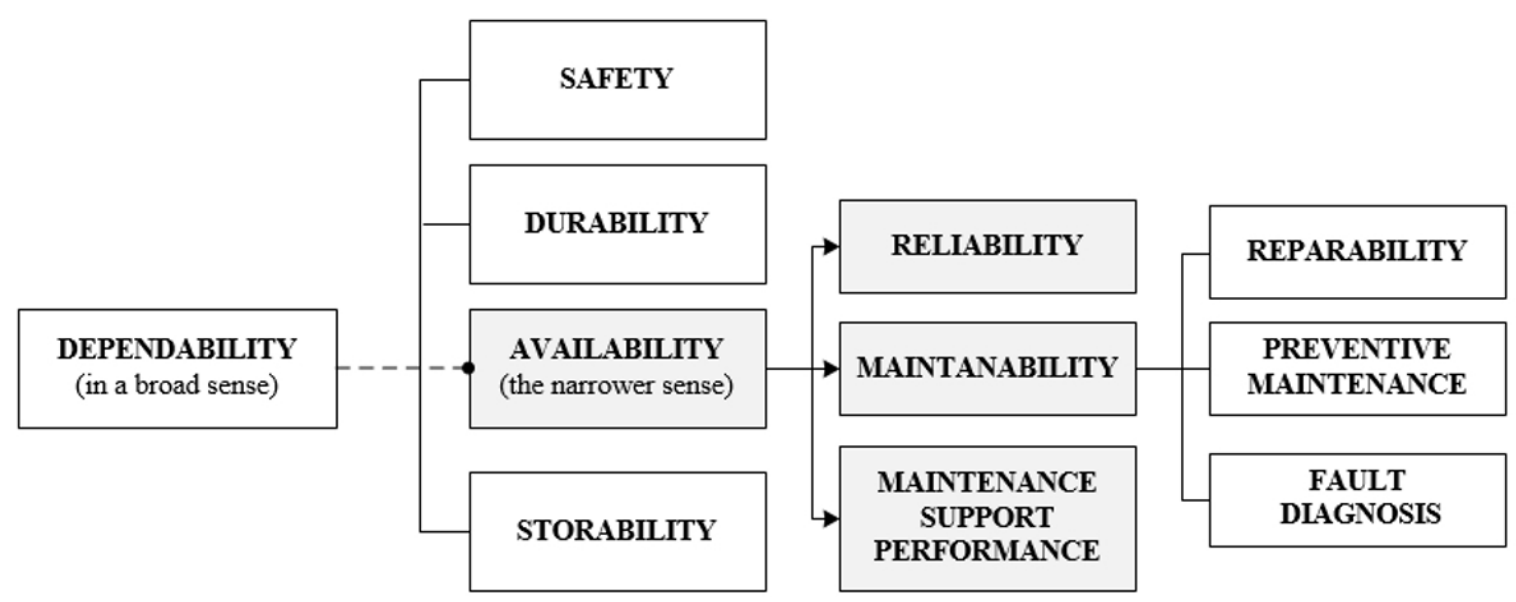

Fig. 8. Dependabilityin the narrow and broadest definition

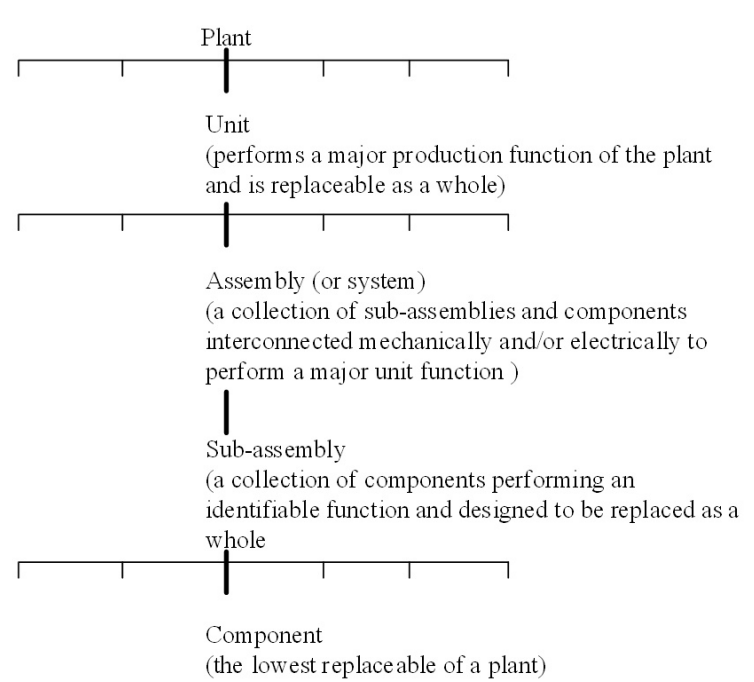

Fig. 9. A plant modelled as a hierarchy of parts [13]

the addition of security are referred to as RAMS $[1,13,22,23]$.

Great attention is dedicated to reliability and availability, maintenance, evaluation, maintainability, less maintenance and maintenance support. The big downside is the assessment of these country-ness posteriori. Built negative values in the product cannot be improved maintenance.

Another problem that must be solved in designing of the content and extent of maintenance is the solution of comprehensiveness in the relationship between individual devices and with whole manufacturing enterprise in a hierarchical structure as is shown in Fig. 9. A structured model of an industrial plant can be invisaged as a hierarchy of parts, ranked according to their functional dependencies into units, assemblies, sub-assemblies and components.

It is equally necessary in designing of maintenance to give more attention to the consequences of failures (even in a hierarchical structure), than to try always ensure reliability, i.e. try to prevent failures as such.

\section{CONCLUSIONS}

Basing on the performed investigation, the following conclusions can be formulated:

- Design of optimal machine and equipment maitenance systems is not possible only on the basis of the theoretical data from the machine operation and its reliability processing (by the methods of apriori reliability), a combination of apriori reliability (especially FMEA) extended to the Reliability Centered Maintenance (RCM) method, is appropriate.

- The RCM method is documented on the MCFV 1050 Basic CNC machine example. The FMEA analysis was performed using the IQ-RM PRO 6 software. In the RCM process 26 of failure modes were defined (after the machine structure, defining functions and error functions -Fig. 3, Fig. 4, Fig. 5), which were divided into failure modes (Fig. 6), and 26 maintenance tasks were found (Fig. 7).

- The result is the folowing proposal: 6 maintenance tasks are performed daily, 2 maintenance tasks are performed weekly, 2 maintenance tasks are carried out at intervals of six months and 8 maintenance tasks are performed as required. The exchange of spindle bearing is estimated after performance from 8,000 to 12,000 operating hours.

- It turns out that it is equally necessary in designing of maintenance to give more attention to the consequences of failures (even in 
a hierarchical structure), than to try always ensure reliability, i.e. try to prevent failures as such (Fig 9).

\section{Acknowledgements}

This article was made under the support of KEGA projects - 024ŽU-4/2016 Improving of education level and its international for students from technical study programmes based on WEB Based Trainingand 022ŽU-4/2017 - Implementation of on-line education in the area of precise technologies with an impact on educational process to increase skills and flexibility of students of engineering fields of study.

\section{REFERENCES}

1. Barlow R. E., Proschan, F. Mathematical Theory of Reliability. John Wiley \& Sons, New York 1965.

2. BurdukA, Chlebus, E. Evalua-tion of the risk in production systems with a parallel reliability structure. Eksploatacja i Niezawodność - Maintenance and Reliability, 2(42), 2009, 84-95.

3. Čuboňová, N. Genetic algorithms implemented for optimization of technological processes. In: Chosen applications of computer modelling in mechanical engineering. Pearson Education Limited, 2015.

4. Čuboňová, N., Kuric, I. Software Program for Training of Control System Sinumerik 840D.In: Academic Journal of Manufacturing Engineering, 9(3), 2011, 80-83.

5. Dodok, T., Čuboňová, N., Kuric, I. Workshop Programming as a Part of Technological Preparation of Production. Advances in Science and Technology Research Journal. 11(1), 2017, 111-116.

6. Galar, D, Gustafson A, Tormos B, Berges L. Maintenance Decision Making based on different types of data fusion. Eksploatacja i Niezawodnosc Maintenance and Reliability, 14(2), 2012, 135-144.

7. Gao, W., Zhang, Z., Ji, H., Zhou, J., Liu, Q. Optimal quasi-periodic preventive maintenance policies for a repairable system with stochastic maintenance interval. Eksploatacja i Niezawodnosc - Maintenance and Reliability, 17(3), 2015; 389-397.

8. Gajdošík, M, Stuchlý, V. Regulation for the maintenance of the $\mathrm{CNC}$ machine tool using a priori and ateriori reliability methods.EDIS University of Žilina, 2016.

9. Golmakani, H. R., Fattahipour, F. Age-based inspection scheme for condition-based maintenance. Journal of Quality in Maintenance Engineering,
17(1),2011, 93-110.

10. Jasiulewicz-Kaczmarek, M. Sustainability: Orientation in Maintenance Management-Theoretical Background. In: P. Golinska. et al. EcoProduction and Logistics. Emerging Trends and Business Practices. Springer, Verlag Berlin Heidelber, 2013, 117-134.

11. Jasiulewicz-Kaczmarek, M. Sustainable Maintenance - the next generation of maintenance management. Proc. of International Conference on Innovative Technologies IN-TECH, Budapest, 2013, 193-196.

12. Jurča, V., Hladík, T.,Aleš, Z. Optimization of preventive maintenance intervals. Eksploatacja i Niezawodnosc - Maintenance and Reliability 3 , 2008, 41-44.

13. Kelly, A. Strategic Maintenance Planning, Elsevier Ltd., 2006.

14. Legát, V., Mošna, F., Aleš, Z., Jurča, V. Preventive maintenance models - higher operational reliability. Eksploatacja i niezawodnosc - Maintenance and reliability, 19 (1), 2017, $134-141$.

15. Moubray, J.: Reliability Centred Maintenance II. Industrial Press, New York NY, 2002.

16. Nowlan, F. S., Heap, H. Reliability Centred Maintenance, National Technical Information Service, Springfield, 1978.

17. Ostachowicz, W., Mcgugan, M., Schröder-Hinrichs, J., Luczak, M. New materials and reliability in offshore wind turbine technology.

18. Rudawska, A., Reszka, M., Warda, T., Miturska, I., Szabelski, J., Stančeková, D., Skoczylas, A. Milling as a method of surface treatment in adhesive bonding. Journal of Adhesion Science and Technology, 30(23), 2016, s. 2619-2636.

19. Rudawska, A., Čuboňová, N., Pomaranska, K., Stančeková, D., Gola, A. Technical and Organizational Improvements of Packaging Production Process. Advances in Science and TechnologyResearch Journal, 10(30), 2016, 182-192.

20. Sága, M., Vaško, M., Čuboňová, N., Piekarska, W. Optimisation Algorithms in Mechanical Engineering Applications. Pearson, 2016.

21. Stuchlý, V., Poprocký, R., Kaczmarek, M. Reliability evaluation as a means of increasing the efficiency of equipment maintenance. Advances in Science and Technology Research Journal, 10(32) 2016, 40-46.

22. Stuchlý, V., Grenčik, J. Calculation of preventive maintenance tasks using RCM method.Euromaintenance XX International Maintenance Conference, Fiera di Verona, Italy, 2010, 207- 209.

23. Stuchlý, V., Poprocký, R. Maintenance of machines and equipment.EDIS University of Žilina, 2014. 